\title{
A Comparative Study of Primary Education System in India and Bhutan (Focus on Indian Rural Primary Schools)
}

\author{
Kinzang Dem*
}

\author{
Ministry of Education, Royal Government of Bhutan
}

\begin{abstract}
Education remains the most vital vehicle taking our journey in life meaningful, valuable and rewarding and with it, one could turn dreams into realities and become successful. Unfortunately, in many developing countries' low literacy rates and low per capita income cause them to below the poverty line. In India, contributing factors like gender, caste, school factors, social factors, and rural-urban inequalities hamper in reasonably achieving minimal development goals. Besides, a high dropout rate from the Indian school system represent a significant concern for a nation marked by one of the largest populated countries in the world. The paper aspires to recognize the reasons for poor retention of students and teachers and their associated issues that impacted educational access in rural primary schools in India. As well, Bhutan too suffers from similar issues such as poor infrastructures, declining education quality, social and economic inequalities, despite many policies, plans, and programs in place. The independent investigation through education access, structure, educational quality and rural primary school curriculum of India is expected to bring prominent understanding about necessary remediation as India and Bhutan constantly face variables issues at the rural front.
\end{abstract}

Keywords: Rural primary school system, educational access, education challenges, education for all

\section{Introduction}

Education is an essential aspect of one's life, and it is the country's most important human capital, and many countries have success stories. India's case is paradoxical. Unexpectedly, India would come out as one of the fastest-growing economies in the south Asian region. Even after six decades of independence, the literacy rate in remote places in India is comparatively lower than towns and cities in India. Factors like gender, caste, ruralurban inequalities in basic education are mentioned as a hindrance to minimal human development goals (Teese, R., Lamb, S., \& Bella, M ,2007). It is comprehended that a lack of essential education contributes to inequality in the economy. In India, the policymakers want to promote education reforms on state policy on the Right to education. The fundamental rights were amended even in the democratic constitution with a noble mission "Education for All" (EFA) goals. Under this developmental goal, all the children from the age of six to fourteen will be provided compulsory free education by the law (Indian constitution, 86th Amendment). Accordingly, policy for right to education and other programs like free mid-day meals, free textbooks, and uniforms, etc. were established to promote universal elementary education and trying to cut gaps among regions caste, gender and social groups. Such initiatives brought positive outcomes in terms of access like increasing financial aids; big improvement of rural livelihood; progressively reducing apparent differences of inequality in education. Enrolment reached at least 96\% since 2009 and girl's enrolment being composed of to 56\% between 20072013.The success story of primary school enrolment in India has been primarily due to various programs and drives to increase enrolment in Indian primary schools, which consists largely of influential schools. They addressed many about to through high-level plans, projects and. significantly, many organizations have come forth to work with the government schools and teachers to improve the learning outcomes of the students.

Bhutanese education system is also discussing these issues through the blueprint project catering to 10 years plan and guidance. However, as an educationist for almost two successful decades, rural primary schools in Bhutan are not picking up unlike the urban schools. Sufficiently investigating the Indian rural primary school development through their successful strategies, comprehensive programs, and other initiatives could aid in 
properly understanding Bhutan's rural primary education as in many practical aspects as they positively correspond to each other when it typically comes to the rural education system.

\section{Methods}

\section{Access, Curriculum and Quality Structure}

The government's embankments on Indian developmental goals were targeted through programs, projects, and policies under the theme "Education for all" further has become a development goal of the millennium. Laws about banning the child labor; the operation blackboard operation and free mid-day meal program; strategizing an improvement of girls' education and infrastructure development is the necessary outcome of this initiative.

Bhutan is discussing key issues such as child labor, major improvement of necessary infrastructure, inclusive education, child rights, etc. through its ambitious programs, projects, and constructive policies. Explicit prohibition to work as domestic workers in the restaurants and tea stalls were added in 2006. The banning of child labor was to grant primary human fundamental rights to the children so that they do not have to enter unpleasant and unsafe working circumstances. Explicit prohibition to work as domestic workers in the restaurants and tea stalls were added in 2006. The banning of child labor was to grant primary human fundamental rights to the children so that they do not have to enter unpleasant and unsafe working circumstances. The child labor act in 1986 was basically to protect children under 14 years from entering into industries like mining and chemicals. Bhutan too adopted its fundamental rights on $18^{\text {th }}$ of July 2008 enshrined in $3^{\text {rd }}$ of articles 35 of the constitution. Adopting the Bhutan's penal code of 2001 and 2004 is the vested interest of the child right and protection.

In both countries, such acts and policies are aimed at urging more children into the schools. A prominent economist, A.K Shiva Kumar, a member of India's national advisory council recognize the enormous long-term benefits of education which are far more significant than the short-term gains of child labor. Then, in 2009 "right to education act" was amended for the children between the ages of 6-14, which provided fundamental right to free, government-funded education in India. However, the activists state there should be strong government intervention as current rules on prohibitions of child labor were indeed ignored to a great extent. In view of census report (2001), an estimate of 12 million children between 5-14 were undoubtedly in the employment market initially and decreased to 5 million (ministry of labor, 2009 survey). The success owe to the banning child labor and enhanced Indian government's aim of promoting free and compulsory education. However, the greater challenge is enforcing liberal education mainly due to economic inequality and social conditions so, the high dropout rates and child labor still predominate. For this, the government of India is undertaking immense measures by funding or supporting primary education. Model similar to the Indian education, the central school project in Bhutan is typically aimed at promptly providing education for equity and quality. The declining enrolment at the rural schools was one of the main reasons for such a project development, and it is enshrined in working guidelines for the central schools.

As "rote learning" is rampant in rural primary school curriculum, the students do not comprehend the text that they are reading so, stunting their reading comprehension skills. On top, the Indian primary school curriculum is highly centralized, biased and irrelevant to rural context. It typically has an intellectual orientation of urban materials and textbooks unsuitable for the rural learners, making it difficult for them to grasp enough knowledge, skills and understanding. The children often have to memorize facts, formula and long texts making extremely incomprehensible. Further, teachers are challenged with large class sizes and inadequate learning materials, so they couldn't engage the students meaningfully (Peter Taylor, 1995). Bhutan's curriculum is also highly centralized, however; recent priority given to the curriculum thinning and relevancy review by the royal education curriculum is expected to improve the teaching learning system and procedure. The Bhutanese curriculum demands understanding, reasoning, creativity, independent learning, etc. Therefore, the writing 
portfolio, keeping journals, project works, reading programs are some strategies emphasizing abstract knowledge and skills expected to help learning to understand and be able to apply in their daily lives.

The school structure is divided into four stages of school education in India. They are namely, primary, upper primary, secondary and higher secondary or high school. The education takes 12 years, the pattern of ten plus two. Because of 2008-2009 reports, more than 88\% of Indian primary schools account for rural India with more than $87 \%$ enrolled in public schools. This indicates enormous challenges for the country. India desires to achieve three parameters: "Universal elementary schools, universal access, and universal achievement. Under these broad concepts, the government took ambitious initiatives like "EFA", "Mid- Day Meal (MDM) programs", "Child Labor Act” and "Operation Blackboard."

Operation Blackboard was an ambitious project started in 1987 as a government-sponsored program. This project just after the Gandhi's National Policy of Education (NPE) of 1986 that a bare minimum crucial facilities to all primary schools in India. Through this scheme, students were provided with necessary education materials and equipment to ease their learning, improve their educational quality and to raise the moral of the teachers. A provisional salary for more teachers in primary schools who taught more than 100 Students Or who teach for two consecutive years.

During the $9^{\text {th }}$ five-year plan, the intended scheme was implemented in upper primary schools with a few more provisions added to meaningfully improve its effective execution. Promotional materials were utilized for teacher preparation programs; broken or non-functioning materials were promptly replaced by the state. The school buildings were intentionally designed to the local need, teaching aids and other equipment were purchased as per local situations and needs. Ultimately, to increase girls' enrolment, 50\% of the teachers were recruited from women folks. An amount of Rupees 12.80 lakhs was spent for girls alone under the same scheme from 1987 to 1994.

\section{Result}

The National Program of Nutritional Support to Primary Education (NP-NSPE) scheme started with 2408 blocks of the country for government or locally supported schools of classes one to five and implemented widely across the country on 15th August, 1995. The scheme provided 300 calories of cooked meals and 12 grams of protein in the primary schools. By 2004, correlating to the convention of the rights of the child, under article 24 of the Indian constitution stated that children would be provided nutritional food adequately. Accordingly, by 2007, the government extended this program to upper primary classes from classes VI-VIIII of 3,479 blocks of educationally deprived blocks of the country. In the same year, the scheme came to be known as (MDM) in schools. Apart from providing cooked meals in most states, the states could choose to offer "dry rations" providing $3 \mathrm{kgs}$ of uncooked wheat or rice to children meeting $80 \%$ attendance. Thus, it's a clear understanding that the India government is making conscious effort in achieving universal primary education through educational reforms such as free (MDM). Such a provision persuaded parents to drive their children to schools but nutritional needs, storage issues, quality of rations, health and sanitation are issues needed urgent attention.

The United Nations Educational, Scientific and Cultural Organization (UNESCO) survey at the beginning of 2004 revealed that the annual salary of primary school teachers with 15 years of teaching experience was more than $\$ 14,000$ adjusting their power of purchase and its GDP per capita was $\$ 3,100$ in 2004 . Their remuneration was much higher than other neighboring countries such as China and Indonesia that were at \$3000 (Gelda, A., \& Narayan, V. et al., 2004). Remuneration remains not only the reason for the deep motivation of rural primary school teachers but also due to performing multiple and irrelevant tasks besides their teaching duties severely affects their sincere motivation for teaching. Responsibilities such as assisting students' immunization, collecting data for the census, election duties during election, supervising meals and distribution of rations in addition to heavy teaching periods are the factors draining the motivation of the teachers. The motivational 
factors for primary school teachers of Bhutan are similar to India in areas of performing multiple and irrelevant roles. In Bhutan's case, a considerable distance from home to schools and vice versa, poor exposure and road connectivity severely hinder the motivational drive of the teachers.

Kremer \& Chaudhury (2005) report on the status of teacher absenteeism showed, $25 \%$ of rural primary school teachers were found absent on uninformed official visits at the schools. They revealed the rate of absentees varied from $15 \%$ in Maharashtra and $42 \%$ in Jharkhandi which is one of the poorest states of India. Interestingly, they also agreed that the salary was not an issue as they mentioned that experienced and educated are paid high but more frequent absentees were found. Therefore, an indication of inadequate bureaucratic system of administration limiting teachers from engaging any sounds decisions and implementing policies, plans and programs.

The high standard contents and materials in rural primary schools make difficult for children to comprehend the texts and other prescribed materials. The children have to memorize facts, formula and long texts often. The prevalent 'Rote learning' practices only hindered achieving knowledge and skills necessary for today's world as well as for the next generation. It means that the challenges of 21 century skills like reading, understanding concepts, applying concepts appropriately and solving problems, And becoming creative are not addressed sufficiently.

Poor teacher qualification, lack of drive for teaching, poor accounting practices, and highly centralized curriculum are prominent reasons for not accessing meaningful educational journey at rural primary schools in India. Anurag Behar, CEO of the Azim Premji Foundation, an education non -profit, too agree that in general, teachers in India do not get enough "in-service or pre-service education" and do not gain support to challenge these issues either. The national survey in 2008-2009 revealed 45\% of the teachers had not undergone training and not studied higher than grade 12. Significant ongoing professional development workshops, training, and continuing education programs to positively enhance the social morals and necessary qualifications of the teachers were found critical for making a difference in the educational outcome of the students. Further, the economic status and social lives of rural people were identified as impeding factors for the education journey of the rural children.

According District Information System for Education's report (DISE, 2012), more than 91\% of primary schools enjoy access to drinking water facilities and $86 \%$ of schools built-in a decade have a school building. However, the government needs for providing other facilities like electricity connectivity, toilets, learning materials, and quality buildings were significant for improving educational access. DISE (2012) reports that 52\% of primary schools have a girls' toilet and $32 \%$ of the schools are connected to electricity. In this way, improving access to education is leading to an increasing enrolment rate over the decades after India's independence but the country is still facing retention problems.

Comparing the literacy growth in 1947 when British rule left India, which represent just 12\% and the record from the 15th official census in 2011 at $74.04 \%$ is an indication that India has made progress economically, socially and globally. India's accomplishment at this rate is amazing, but there is still growing concern about the majority of people in India who cannot read and write especially in remote pockets. The government enactment of free and compulsory education under the age of 14 seems ineffective in containing the problem of illiteracy that exists in large extends in rural settings even now. The fact that female literacy is still far behind than male remains a critical concern of the government of India. It along with NGOs through government ads, campaigns and programs are being carried out to enhance awareness programs on the importance of girls' education. It has also come up with the particular rules to bridge the gender gap and also rules to provide equitable opportunities and rights to girls' education. 


\section{Discussion}

\section{The Impacts and Challenges}

The results of amazingly increasing numbers of schools headed to an increasing number of student enrolments each year. The improvement of staff and enrolment of girls has been much seen. Since 2012, 96.5\% of all rural children between the ages of 6-14 were enrolled in the schools. This is distinct from the Annual Status of Education Report (ASER, 2012). With the enactment of children's right to education in 2012, the Indian government has worked hard to offer rural schools with adequate infrastructure which lacked critically hitherto.

The low retention problem in rural primary schools is not surprising. Though the government is trying to meet $100 \%$ enrolment, students fail to complete even the upper primary school levels. Soha Moitra of Child Rights and You (CRY) mentions three big reasons for the dropout; poverty, availability and accessibility forcing children out of schools. In addition factors like student-related factors like low esteem, low mother's education, early marriage, low-income, poor social skills and insecurity; school factors like a limited relationship between schools and community, inadequate school practices like teaching methods and materials, an irrelevant curriculum, a lack of orientation and vision, large size classrooms, exam-oriented practices than practicality; constructing factors like limited perception about teachers and students towards schools and against each other, teachers' ill-treatment of students, dislike for schools due to boredom and perception of pointlessness of attending schools; political, social and economic factors that schools are connected to in-terms of demographics and labor markets contribute to dropout issue and be a big issue in India. The Ministry for Human Resource Development (MHRD, 2011) revealed 62.1 million out of 84 million children are out of schools in India and $20 \%$ of children fall in the group of right to education. The dropout remains moreover, an issue in Bhutan and increasing records for the last decades could be found from National Statistics Year Book(NSYB, 2013); Policy and Planning Division, Ministry of Education(MoE, 2011) and (UNICEF, 2009). As school dropout is a complex problem and required a comprehensive study, the voices of already out of school children documented and captured to understand the complexity of the problems. This was intended for the policymakers and educationists to gain ground on the issues and discuss them.

Despite India's government's initiatives of (NP-NSPE) on 15 August 1995 to persuade more students and keep them. The mid-day meal plan under the same scheme forced school children in India with a mid-day meal every day and has become successful mainly because of its nation-wide outreach approach. In the process, quality of education was widely affected as teachers have to take up supervisory and accounts related works. With increasing rates of enrolment, much of the teachers' time had to be spent supervising and distributing meals. The teachers in remote primary schools claim that they fail to carry out their primary duties of teaching because of the assignment of many unrelated duties by the more superior authorities. Teachers are merely passing students to the next grades without a meaningful learning. Because of this, children are placed in challenging situations in their later stages, as they need to write competitive examinations and have to undergo a strict assessment process. MDM supervision and distribution were mentioned as the unrelated duties hampering their roles as teachers and being unable to maintain quality learning in schools so hindered their motivation to teach effectively. Rani \&Sharma (2017) in their study about MDM in Jammu province illustrates the perspectives of teachers on the MDM Scheme. They report that $92.50 \%$ of teachers are wasting their time meaning they do not receive sufficient time for teaching and learning. $96 \%$ of teachers claimed the quality of education suffered due to having to attend MDM related activities. 93\% responded it took away their huge time and energy in its implementation. Also, not meeting nutritional needs, sanitation and hygiene and infrastructure to store the ingredients remain factors affecting the delivery of effective education. On the contrary, central school projects of Bhutan focus on free meals daily which raises the eyebrows of many small schools in rural areas as some of them do not get even one meal. However, Rani \& Sharma(2017) suggest if such programs are to be implemented covering strict guidelines with the assignment of roles and guidelines for strict compliances to adhere would help in providing equity and quality educations. 
The nature of how the schools teach and how students experience in rural schools seem to contain an immense gap. This sets them at a disadvantage side against their urban counterparts. The circumstances of the environment are denying the security and emotional adjustment necessary for performing learning tasks at the formal schools. Taylor's(1995) article on "Contextualizing the Curriculums in Rural Primary Schools: The Role of Agriculture " claims that the experience could be rich with certain environments of disadvantaged children but in a general sense, their learning horizon is limited in many school experiences, therefore, the curricular activities that make most of their environmental experiences could be valuable to them. In this view, practitioners are focusing on the emphases of rural values, people's knowledge, and rural education programs to continue to be a foundation. It is even more significant to understand that children known as the disadvantaged group have to experience consequences of circumstances that are unconducive for learning either because they have problems with their urgent social needs or special education needs. In the case of most rural places in India, basic needs are short in supply and educational needs are unmet making difficult to enforce the ideas about educational content and process.

Language is considered as one of the reasons for hindrance to educational journey in most rural places in India. It has more than 400 spoken languages and 22 official languages. It is empirical that language as a means of communication, thinking and learning process impact education. In early primary schools, children have to study in a language they cannot comprehend thoroughly places them at a serious disadvantage side and limiting the development self-confidence and self-esteem necessary for life. At the initial stage, children could appreciate the literature in their mother tongue. However, when they enter primary schools, often the language is different from their home setting so children encounter difficulty in understanding letters and phonology. Reading becomes a daunting task that slowly demotivates students with no option but to abandon the school itself. In Bhutan, Dzongkha and English are two official languages. The case is the same with Bhutan too. The rural children struggle to understand English and its use due to limited exposure to the language. On top of that, the children find confident to use home language and Dzongkha, a national language so they get unmotivated to learn English. In that manner, quality education is hindered to a large extent compared to their urban counterparts.

Indian school curriculum policymakers are undoubtedly aware of the problem and have introduced a curriculum policy of teaching in primary schools in their mother tongue to address the educational needs of the students. But in real education practices, two reactions have become prominent "Diversity is considered a nuisance to multilingualism, a socioeconomic burden, privileged practices of preference for homogenization and standardization. "Minority languages are considered inadequate impoverished and underdeveloped and consequently, unfit for educational and scientific use” (Mohanty K. Ajit, M \& Mahendra,K., N.etl .pp. 180-181). Because of suppression of minority languages and incomprehensible formal languages dehumanized the minority groups and their languages have become the barriers to their educational journey and their marginal lives. India's diversity with multiple dialects, spoken and official languages stand issues in understanding or implementing curriculum meaningfully. In the same pipeline, native language is their right, so the central government established the provision of Mother Tongue with two others, Hindi and English as formal instructions at primary schools for reasons as their desire to maintain their cultural identity. On the contrary, texts and materials are widely written in Hindi, their national language and English, the language of the significant world in this globalized world because of its connectivity and scope. So, uniform language provision can be researched for further improvement in the education system, and alternative forms of relevant curriculum could be developed to meet the social and educational needs of the disadvantaged children in rural schools. One example provided by Peter Taylor is conceptualizing agriculture, as a subject that could be valuable to rural children.

Comparing Indian teachers to Finnish teachers, one could see an enormous difference in the status and qualification of teachers. Teaching status is high in Finland, enrolled only after six years of master's level intending to offer deeper based content and pedagogy. Gaw(2008) mentioned that Finnish teachers are not only 
qualified but equally possess more superior status. The Finnish schools are one of the superior ranks in PISA ratings. As many researchers claim teacher's quality affecting student's learning outcomes, the teachers in Indian rural primary schools consist of poor quality teachers marked by low qualification, unsupportive attitude and low obedience practices affecting the quality education in India. Many teachers are unprepared to deal with methods and curriculum practices effectively. On top, Inadequate teachers, high absenteeism and poor support besides having to teach multi-grade teaching, textbooks involving a high level of understanding and students with varying levels of learning abilities accountable for poor learning outcomes are mentioned by Dhir Jhingran who is twenty years old of working in rural primary education. The teachers' significant absenteeism indicates that a strict regulation needs to be in place to make teachers more accountable to their professions as well as to the stakeholders and most importantly to the learners. Teacher retention remains an issue in Bhutan too. So, a recent pay increase for teachers who are going to be the highest in the civil service group of Bhutan is intended to retain teachers as well to make teaching an attractive profession. However, researchers have confirmed that pay as not a sole issue. Therefore, allow teachers to see how other factors could be considered for uplifting the morals of the teachers and motivation for teaching. In India's case, because of the huge population, such a regulation could be challenging and it lacks different attention and strict directives. Some of them could be investing in professional growth of teachers through in-service training programs for teachers in rural schools, checking teachers' responsibility through students work, reports, assessment records, class observations, etc. and improving the status of teachers by reducing workloads and assigning only teaching related works which could enhance teachers' motivation. They could be provided with a platform to share their feedback, recent findings, and experiences so that the curriculum can be reviewed and developed into the one that suits the rural communities. However, it is unmanageable in India as the curriculum is highly centralized which prevents them from executing any bold decisions. In this regard, it is crucial to turn the tables by distributing some independence in curriculum delivery as well as making teachers accountable for the decisions they make. It is expected to generate positive results in the performance of the children as they are the ones to best understand the students' needs.

Under Operation Blackboard project, educational facilities improved. The "National Policy on Education" in 1986 (NPE, 1986) highlighted a "minimum level of learning"(MLL) to achieve universal achievement that provided space to affect the quality of education in rural schools. This strategy was carried out under the establishment of the District Institute of Education and Training. The District Education Revitalization Program (DERP) was launched in 1994 to universalize primary education in India by reforming and strengthening the existing primary education system. UNICEF and other international programs supported The DERP in opening of 16000 new schools including 84000 alternative education schools of about 3.5 million children.

Under Education For All Program, The NPEGEL( "National Program for Education of Girls at Elementary Level"), with emphasis on girl's education started in 21 states of 3,000 blocks of India were identified with a low female literacy rate. The formulation of NPEGEL for girls of underprivileged or disadvantaged backgrounds was to achieve universal primary education under the grand scheme of "Sarva Shiksha Abhiyan"(Education for all). This program was undoubtedly intended to sufficiently develop the self-esteem of girls who would have been deprived of primary education because of social factors that provided diverse roles to them.

The government of India properly recognized the significant roles of girls in reasonably achieving universal achievement, universal elementary and universal access in education. Therefore, it came up with a strategy of mobilizing girls 'education through local community, teachers and NGOs under the same umbrella of "Education for all". The government constructed girl friendly infrastructure, hired specific instructors for women and girl education, provided supplementary teaching aids for girls' education and established bridging courses and flexible timing. All these provisions were to raise the literacy level of girls and to achieve equity in education. Like other developing countries, India's literacy focus for girls then becomes the fundamental aspects of social and economic growth. 
The curriculum policy in Indian schools is indifferent from many countries. Indian education systems aim at providing children with opportunities to recognize and celebrate their uniqueness, enhance the potential to address the challenges of the 21 st century and develop skills required like effective communication, problemsolving skills, critical thinking, inquiry and investigation skills, social, personal interaction and self-awareness with a key focus on literacy and numeric skills. Gaining such skills would be virtually impossible as the traditional method of teaching "rote learning" has been in practice as far back as 200 BC. 'Rote learning' not only limit children from achieving knowledge and skills necessary for today's world but also impede learning for the next generation. Its implication would be even bigger than now as every generation is expected to do better with modern learning styles and pedagogies. The modern educationists believe that students needing to memorize the texts in parts do not generate any understanding of concepts and ideas. Hence, students lack creativity and necessary innovations of the globalized world.

Despite many initiatives of the Indian government, a matter of concern in interior areas of most rural primary schools is cleanliness. Drinking water, electricity connectivity and sanitation remain. However, the issues are not yet resolved. Girls are still at risk because of the absence of alternative schools. The national data indicates about $10.21 \%$ of inhibition or villages do not contain alternative schools. Therefore, parents are concerned about their safety and do not wish to direct them to schools. Besides, lack of buildings or unusable classrooms, inadequate teachers, infrastructure, drinking water, and toilets are issues affecting their teaching and learning hinders the learning and teaching process.

\section{Conclusion}

Bhutan carefully took its first diplomatic ties with India and it has been undoubtedly benefiting from India especially in extensive trade and education. India supported a milestone in the development of the modern education system in Bhutan. A remarkable fact is that in the earlier days, Hindi was one of the instructional languages in Bhutanese schools and many subjects of studies were taught in the Indian education curriculum. It becomes paramount to recognize the Indian Education system as the Bhutanese modern education system was influenced by their system. The undeniable fact is that rural primary education systems in Bhutan face similar challenges in meaningful access, essential quality, and necessary infrastructure. Studying India's rural education system would significantly contribute to understanding, reflecting, creating and developing a Bhutanese education system.

Both Bhutan and India are growing economically with the increasing concern of governments that the success of education is paramount to economic development. The governments are consciously placing their efforts into identifying issues related to education. Primary Education is the foundation on which the large system of education would be laid is given priority in terms of access to education, improving both physical and organizational structure and offering platforms for researchers to investigate on the relevancy of the curriculum, programs, projects, etc. which the central government and other partnering agencies have instituted. While some innovative programs in rural primary schools of both countries have turned out to be successful, others needed better support and accountability practices. For instance, the Indian "Education for all" a scheme for free and compulsory education for children of 6-14 years in India was successful because of its wide out-reached programs to the rural primary schools but leaves room for criticism like inappropriate implementation of programs and inadequate directions. The central school feeding program is still criticized for not meeting the social equity and quality food program widely because of inadequate government budget.

The aim of both the countries is to increase enrolment in rural primary schools, construct sufficient classrooms, build a more efficient system of road connectivity and electricity, and provide meal support to enhance their nutrition to assist in improving learning outcomes. One such is the girls' education program in India that bridged the gender gap in the education system and the child labor act has undoubtedly become a fundamental human right that modestly improved an equity issue in rural primary schools. Conversely, students' social and school 
factors and political and economic related factors are making difficult for any country to realistically achieve universal elementary education, universal achievement and universal access to education. Learning the success and failure of policies, plans, and programs of rural primary schools, leaders, policymakers, researchers, executives, and educationalist could draw attention to how possibly they could improve the rural primary education system in terms of education quality, access, structures, and curriculum.

Further investigation could be undertaken with proper regards to the possible reasons for the deep motivation of teachers and notable absentees, a typical workload of both teaching and other unrelated responsibilities as these represent the contributing factors powerfully affecting quality educational access of any educational context. The comprehensive programs gearing to meaningfully improve the economic status and social lives of rural communities could be considered. One such could be investing in rural cooperative farming and rural projects to carefully cut their economic disparities of rural people and positively enhancing their affordability for an economy as well as education. Indian government could also streamline the already existing programs by enforcing strict compliances and defining roles that would not affect teachers and their teaching jobs. The 21stcentury teaching and learning pedagogies could be adequately explored and the skills necessary for 21st graduates to be universally adopted as a nationwide program with adequate trainings. As India is still struggling to achieve equity and quality education, there is further scope for extensive research in new pedagogies, learning styles, teachers, well-being, girls' education, rural education, narrowing the gap between rural and urban education etc. More investigation in educational needs of people from different backgrounds must be carried out so the quality of education is not compromised and educational access could be prioritized.

\section{References}

Betaille, T .(.2002). Elementary Education in India. ICIC Social initiatives.org. India.

Bhutan Education Blueprint. (2014 -2024) Rethinking Education. Ministry of Education. Thimphu.

Chaudhri, D., Jha \& Raghbendra.(1993-94) \&(2004-2005,). Child Poverty, Demographic Transition and Gender Bias in Education in India: Household Data Analysis. ASARC Work in Paper. 2011/17.

Chatterjee, B. ( 2006) Education for All: The Indian Saga, Lotus Press. New Delhi. Date of access:17/3/ 2015.

Chate, C. (ed.). (2012). The Oxford Handbook of the India Economy,Oxford University Press. New York.

Childline .(2015).Night \& Day. Retrieved from childline india.org, Date of access :(2015 March,17), pp.1098.

Chu, S \& Wu, H .( 2010). Understanding Literacy Practices in Culturally and Linguistically Diverse Children's Homes. Johns Hopkin University Press. US.

Connor,M., et al.( 2005).Journal of school psychology, pp. 343-375. Elsevier Hd.US

Constitution of Bhutan.(2008). Article 3(35), Children's Rights, Bhutan. Eritrea Institute of Technology.( 2015) - Mai Nefhi Asmara, Eritrea. Rapid Acceleration of Progress is needed to achieve universal primary education http://data.unicef.org/education /primary\#sthash.7ydlLoIo.dpuf.

Gaw, B .( 2008). How good is Australian education? : Education, science and public policy Melbourne University Press. Melbourne.

Gelda, A., \& Narayan,V., et al. ( 2014). 'Needs Improvement': Despite Progress, India's Primary Education System Has Ways to Go. Knowledge @ Wharton. University of Pennsylvania, Wharton.

Gyamtsho, S., Swabey, K., \& Pullen, D. (2015). Capturing the voices of school dropouts in Bhutan,AARE Conference Proceedings, 29 Nov - 3 Dec 2015, University of Notre Dame, pp. 1-11. ISSN 1324-9320 (2015) [Refereed Conference Paper].

Hueler \& Friedrich .(2005 August 29). Primary school attendance in India. huebler.blogspot.com/atom.xml Kremer, M., et al.( 2005).Teacher Absence in India: Snapshot. DOI: 10.1162/jeea.2005.3.2-3.658

Kuenselonline .(2019 June 8). Additional allowances for teachers only in 2020. Date of access: 29/6/2019. 
Mohanty K. Ajit, M \& Mahendra,K .( 2014 November 17). Govt plans law for a complete ban on child labor. Times of India.

Rani, R., \& Sharma, D.( 2017).Problems Faced by Teachers in Implementation of Mid -Day Meal Scheme at Primary School level in Jammu Provence, International Journal of Development Research, 7(8), pp. 1471814722.

Rena \& Ravindra .( 2007).Factors Affecting the Enrolment and Retention of Students at Primary Education in Andhra Pradesh-Village Level Study. Essay on Education, 102(112).

Samdrup. (2011). Policy \& Planning Division, Ministry of Education. Bhutan

Sampath,G . (2016). The HINDU, India's National Newspaper. Why children drop out of primary school.UPDATED: DECEMBER 11,13:30 IS

Singh, N., \& Badiger.(2017). Knowledge of Rural School Children about Mid- Day Meal Program, 6(1), pp. 1248-1258. DOI:http://dx.doi.org/10.18782/2320-7051.5118.

Taneja, A .(2018 ).The high dropout rate of girls in India, Date of access: 3/4/19, theirview@livemint.com.

Taylor, P. (1995). Contextualising the Curriculum in Rural Primary Schools: The Role of Agriculture.E D40307, pp.88 Overseas Development Administration, London.

Teese, R., Lamb, S., \& Bella, M.(ed.).(2007), International Studies in Educational Inequality:Theory and Policy, vol 3, pp.207-238, Springer, The Netherlands. 